Journal of Social Sciences 7 (2): 182-185, 2011

ISSN 1549-3652

(C) 2010 Science Publications

\title{
An Developing Alternative Tourism Potentials: A Path Following the National Co developers on the Phu Phan Panges
}

\author{
Chanyut Hankhampa and Songkoon Chantachon \\ The Research Institute Northeastern of Arts and Culture Mahasarakham University, \\ Mahasarakham 44001, Thailand
}

\begin{abstract}
Problem statement: The development of alternative tourism was necessary. The objectives of this research were to study: (1) the history of group collaborating in Thai National Development on Pu-pan Mountain Range, (2) the potentiality of tourism according to the keeping on track of the group collaborating in Thai National Development on Pu-pan Mountain Range and (3) the appropriate management in alternative tourism. Approach: The research area included Sakonnakon and Kalasin Provinces. The samples as informants were selected by Purposive Sampling, for 168 persons. The instrument using for collecting data consisted of the Interview Form, the Observation Form, Focus Group Discussion and Participatory Workshop. Data were classified into groups, investigated by using Triangulation and analyzed according to specified goal. The findings were presented in descriptive analysis. Results: (1) the historical background, Thailand was governed by soldier authoritarian system in 1964 in the age of Marshal Tanom Kittikajon who made a revolution. As a result, people were under political pressure with maltreating and suppressing people who loved democracy very much by accusing that they were communist party of Thailand. Finally, they collaborated in fighting with communist party for helping the suffered people. Then, they were suppressed by the government. There was fighting until the citizen had death and loss. This group stopped, (2) the problem situation in managing the recent tour origin, found that it was a lack of entrepreneurs leading the local tour, who had knowledge and competency in local culture. The tour places were not developed. There was a lack of tour guides in each place, in explaining for the tourists, public relation and facilities, (3) the appropriate management of alternative tourism on Pu-pan mountain range, consisted of 5 aspects as follows: (1) the service, (2) the tour activities, (3) the environmental condition, (4) the management and (5) the marketing enhancement. For group service, there were 4 levels of alternative tourists: (1) the consumer group with high price, (2) the consumer group with moderate level of income, (3) the consumer group with not high level of income and (4) the consumer group as students. The appropriate activities should be managed for the consumers. Conclusion/Recommendations: The continuous activity implementation in Pu-pan mountain range, if it was regular developed, would affect the community economic system since the place not only related to historical story, but also had fertile nature for creating the tour atmosphere very well.
\end{abstract}

Key words: Alternative tourism, tourism potentials, ecological system, environmental conservation

\section{INTRODUCTION}

According to power of the above trend, the approach of development in tourism model focusing on guidelines for maintaining ecological system of nature, was occurred. The occurred approach was an ecological tourism. In the present, the trend of travelling in natural area, played more roles. So, the related work units prepared for readiness serving this kind of tourism by developing the model activities in the area including more varieties, as well as searching for and developing the new tour places, controlling and managing so that there were not too much tours in the area until it was more than competency level in serving of area and the important thing as the support for local participation in being the tour guides, the service of staying places for tourists and selling of souvenir for the tourists.

When the trend of tourism in ecological tour was increasing, many sectors were concerned that whether the ecological tour would help in conserving the natural environment or accelerator for more natural damages.

Corresponding Author: Chanyut Hankhampa, The Research Institute Northeastern of Arts and Culture, Mahasarakham University, Maha Sarakham 44001, Thailand 
Therefore, there was a new approach as an alternative tourism in order to serve the need of tourists by using calm , peaceful and recreation as selling points. In addition, the tour lists were presented in new item categories such as tour in city, sport tour, cultural tour, agricultural tour and health tour. In order to spread the tourists from natural area to your in city. However, in tour management, systematic and efficient tour management focusing on community participation and consideration in characteristic of each area, should be performed.

Pu-pan mountain range was another area with various tour managements including fertile tour resources. But, it couldn't completely serve the tourists' needs. The tour route according to the trace of those who participated in Thai National Development, the creators of great history on Pu-pan Mountain Range, including difficulties in livelihood before maintaining Thailand in the present time. The interesting stories for the descendants, should be the traveling path which could serve the need for Alternative Tourism, as the focus on environmental conservation and natural resources, the study and learning in the environment and natural resources causing the awareness and conscious in environmental conservation as well as participation of citizen from grass root level in order to include the correct development and appropriate spread income into locality for conciseness and clearness.

\section{MATERIALS AND METHODS}

The studied area included the North-eastern Region of Thailand. In this research, the areas were specified in studying on Pu-pan Mountain Range at 4 Districts: Muang-sakonnakon District, Pu-pan District, Goodbag District, Sakonnakon Province and Na-koo District, Kalasin Province. Qualitative Research Methodology was administered in this study by collecting data from documents. The samples were selected by Purposive Sampling including 40 expert group, 88 key informants, 40 general villagers, total of 168 persons. The instruments using for collecting data consisted of the Interview Form, the Observation Form, the Focus Group Discussion and Participatory Workshop. Data were investigated by using Triangulation based on specified issues in the research objectives. The findings were presented in descriptive analysis.

\section{RESULTS}

The research findings were as follows.

The history of the group: Participating in Thai National Development on Pu-pan Mountain Range,
Thailand was governed by soldier authoritarian system in 1967. In that period, Marshall Tanom Kittikachon's government mad a revolution. As a result, citizens were under political pressure with maltreating on people who seriously loved democracy. In addition, there was a group of Thai National Development or Communist Party of Thailand persuading the citizens to collaborate in fighting for democracy. At that time, there was an establishment of resident soldiers participating in studying and training from Soldier Courses, collecting for provisions, finding news, reporting news, until they were conquered by government. There was a fighting until the citizens were dead and lost. Their livelihood while participating in the party, was to adapt themselves based on conditions of each locality and sufficient life by finding natural food.

There were 2 kinds of tourism by keeping track of the group of Thai national development on pu-pan mountain range: The tourism on nature and history, current problems including the lack of entrepreneurs in local tourism, local freelance entrepreneurs with knowledge and understanding in local culture or tour sources, with specific competency in being tour guides, items producers in souvenir for tourists, souvenir shop in various places, regular local guides in each place for explaining for tourists. For the overall readiness preparation in tour places still lacked of readiness including the toilet room, garbage bin, label showing direction, resting place during travelling, security guard and brochure informing the journey route, restaurant, Educational Tourism, as well as Religious and Cultural Tourism.

There were 5 appropriate management in alternative tourism on Pu-pan Mountain Range, were as follows: (1) the service, (2) the tour activity, (3) the environmental condition, (4) the management and (5) the marketing promotion. For the consumer or target group, the consumers or alternative tourists: The route keeping track on persons participating in Thai National Development on Pu-pan Mountain Range, classified into 4 levels: (1) the high income consumer group, (2) the moderate income consumer, (3) the little amount of income consumer and (4) the Secondary School Student Consumer. For journey management of alternative tourism on Pu-pan Mountain Range, the route keeping track on those who collaborated in Thai National Development on Pu-pan Mountain Range, at 4 Districts, as a new package, travelling in one day, consisted of these activities: viewing the historyvisiting the cave/geology of beautiful nature. 


\section{DISCUSSION}

According to research findings, could be discussed as follows.

The history of group of people: Collaborating on Thai National Development on Pu-pan Mountain Range, after Thailand was taken over by Japanese Soldiers in 1941, Preedee Panomyong, acting King of His Majesty the King Anadamahidon, set up Liberal Thai for secretly opposing Japan. Tieng Sirikan knew that plan at the beginning, he and his Esan Representative Friends, on behalf of leader of low level citizens in Esan Region, had responsibility in establishing Liberal Thai in Esan which was one of the biggest Liberal Thai of the country, including the troops power as thief gang especially on Pu-pan Mountain Range, Sakonnakon Province, the first point sine Pu-pan Mountain Range had an adequate geography as a forest, cliff and cave narrow space for hiding the weapons, including major aims: to have an opposed movement opposing Japanese Army. Meanwhile that group was accused of communists especially the political competitor, student group and citizen. As a result, there were more people with common ideal. Later on, they were strictly suppressed by the government. Marshall Sarit Tanarat made a revolution in 1958, He implemented seriously by putting many people to death. When people were mistreated, they fought with the government officers by using the gun on the 7th August 1965, causing "the exploded gun noise day." It was a big conflict in power class, slandering, taking advantage. Consequently, the conflicts happened. It was supported by Sanyawiat (2009) statement that the human beings' conflict including: the disagreement, doubtfulness, quarreling, negotiating, disputing, taking advantage, exploiting. fighting and killing, making war, controlling, governing and managing. However, there were good points between government and communist party of Thailand, occurring after the war, there were asphalt roads into the area, constructions of the bridge crossing the river as cement bridge. Consequently, Esan used to be overlooked in the former time, had more public utilities.

For problems in tour management, people I the area didn't understand tourism, the communists: Natural and historical tour places were not developed for serving the tour, lack of fund for developing facilities for tourists. There were 5 disadvantages including: (1) planning, the committee had to be appointed for taking care of many aspects since there were no leading guides for natural and history tour of communists, (2) the body of knowledge management, the group of those who collaborated in Thai National Development for asking knowledge as well as places, managing the fund, (3) the management in establishing committee of community level and the study of tourism as well as natural resource maintenance, (4) the direct of citizen organization cooperating with public sector and private organization as well as other sector as holistic and integrated and (5) the control, following up and evaluation the citizen organization obtained learning, analysis, research, planning, following up and evaluating by themselves from different activities affecting the tour places. It was supported by Pramahasuti A-pa-ke-ro (2004) findings of the study in potentiality of local community in promoting the conservative tourism, found that the factors had relationship with potentiality for enhancing ecological tour including: the personal factor, the community factor, the environmental condition. Furthermore, it was also found that the samples with knowledge and understanding in ecological tourism, had management and participation among the tour network with community and government, showing more potential than the group without knowledge and understanding in ecological tourism, the lack of service, planning for serving tourism and no participation among networks both of community and government.

For potentiality of tour management keeping track on the group who collaborated in Thai National Development on Pu-pan Mountain Range from natural and historical tour places, found that there were current problem situations as: (1) the lack of local tour entrepreneurs, (92) the lack of souvenir producer for tourists, souvenir shop in tour places, (3) the lack of regular local guide in each place for explaining for tourists, (4) the readiness preparation in tourism, it was lacked of overall readiness, (5) the lack of Educational Tourism as well as Religious and Cultural Tourism. It was tourism of local culture and local art and (6) the lack of care and support from both of public and private sectors by letting the villagers and community take care by themselves which might cause no system. Yodpanya and Kadwua-Donko (2002) studied "Kadwua Don-ko," found the disadvantage in following issues: (1) the impact on physical environment with more damage, (2) the systematic management, (3) the people's conflict, (4) the lack of organization to take care or control. So, it was necessary to manage the cultural heritage to be systematic.

There were 5 appropriate managements of the path of alternative tourism as follows: (1) the service, (2) the tour activity, (3) the environment, (4) the management and (5) the marketing promotion. 
Customer or Target Group: the customers or alternative touris: the route in keeping track of those who participated in Tai National Development, could be classified into 4 levels: (1) the high income customer, (2) the moderate income customer, 3) the little amount of income customer and 4) the Secondary School Student Customers. For appropriate management of alternative tourism on Pu-pan Mountain Range: the route in keeping track of those who collaborated in Thai National Development on Pu-pan Mountain Range, at 4 Districts, new package, one day tour, including the activities as: viewing history-visiting the cave/geology in beautiful nature. It was supported by Srisantisuk (1996) statement that the culture was a factor pushing human beings in being able to produce more energy as well as consume energy and controlling society. The cultural development caused by technological progress. It could be seen that the techno-economic in society for developing the relationship with environment. When there was relationship, the human could be able to developed social system until the person's thought was finally determined. The cultural system would control social system. The social system would control each human's mind system in society. This research : the appropriate management of alternative tourism on $\mathrm{Pu}-$ pan Mountain Range, was able to develop economic vale and worth for community people. Moreover, it could make people in community and society be proud of their local culture and resources affecting the existed and sustainable resources further. It was supported by Amkha Saeng-Ngam (2009) Having got the ideas and realization of thecommunity cultures and also the principal idea ofthe community's tourism management which says“The amount of money having earned cannot bealways regarded as a sole indicator of success inmanaging the tours"; "The money gained solely a factor that drives the working process toward the aim". The real goal of tourism management by community is to conserve ancient sites, significantly, it is managed to maintain customs and cultures. Particularly, when the community people have learned altogether the system of work and they have altogether renovated festivals and customs, as well as feeling proud. Best of all, their relationships have become amicable, friendly and in harmony. Their happiness means everyone is happy. Having happiness in common is regarded as a great success.

\section{CONCLUSION}

The tourism enhancement in learning dimension, tourism activities were organized by managing with focus on the tourists to gain knowledge in tour sources from travelling, for instance, to trace back the history according to the keeping track on the persons who collaborated in Thai National Development on Pu-pan Mountain Range, the youth camp for providing different aspects of knowledge, sea ecological system, tour route for learning in culture, history, which would affect the tourists' behavioral changes in long range. The important thing was that every sector had to participate in management including: (1) the grouping as an organization for management, for example, community enterprise, cooperative group, club, (2) the members in organization participated in management and different service activities, (3) the management activities fort staying place with clear rural culture including: the implementation plan was specified, the implementation according to the plan and follow up and evaluation, budget determination in capital budget, implementation budget and staff for implementation with effectiveness, (4) the rule and regulations were specified for the tourists and members participating in activity of staying place with rural culture, (5) the advanced reservation system and registration for knowing the information relating to the tourists, were specified and (6) the product produced by local wisdom were sold as souvenir items.

\section{ACKNOWLEDGEMENT}

The research has been supported generously by the Mahasarakham University Research Fund. The researchers would like to express their sincere appreciation for all of the support provided.

\section{REFERENCES}

Saeng-Ngam, A., S. Chantachon and P. Ritthide, 2009. The organization of cultural tourism by the community people in the region of Toong Kula Rong Hai. J. Soc. Sci., 5: 342-347. DOI: 10.3844/jssp.2009.342.347

Pramahasuti A-pa-ke-ro, 2004. Network: Nature, Knowledge and Management. 1st Edn., Project enhancing Learning for Happy Community, Bangkok, ISBN:974-924-300-5, pp: 75-76.

Sanyawiat, S., 2009. Sociological Theory: The content and use of Basic Guidelines. 1st Edn., Contract agreement progresss Chulalongkorn University Printing, ISBN: 9789740318583, pp: 102-103.

Srisantisuk, S., 1996. Sociology of Aging Condition: Truth and Anticipation in Thai Society. 1st Edn., Chulalongkorn University Printing, Bangkok, ISBN:974-633-210-4, pp: 142.

Yodpanya, S. and Kadwua-donko, 2002. System of Social and Economic Relationship in Trader Group. 1st Edn., Master of Art Thesis, Silapakon University, ISBN: 974-653- 547-1, pp: 96. 